\title{
ANALISIS TEKNIK BORROWING DALAM PENERJEMAHAN NOVEL KARANGAN L. FRANK BAUM THE WONDERFUL WIZARD OF OZ KE DALAM BAHASA INDONESIA
}

\author{
Subari \\ SMAN 3 Mataram \& Universitas Mataram \\ subariab@yahoo.com
}

\section{ABSTRAK}

ABSTRACT

PENDAHULUAN
Penelitian ini adalah jenis penelitian kepustakaan yang bertujuan untuk mengetahui teknik borrowing (pinjaman) yang digunakan oleh seorang penerjemah dalam menerjemahkan novel Frank Baum berjudul The Wonderful Wizard of $O z$ yang diterjemahkan oleh Dewanti pada tahun 2018. Teknik borrowing yang dianalisis dalam penelitian ini adalah pure borrowing (pinjaman murni) dan naturalized borrowing (pinjaman naturalisasi). Data diambil dengan membaca berulang kali dan membuat daftar kata-kata borrowing yang ditemukan, dan kemudian menjelaskannya dengan mengutip kalimat kedua novel tersebut. Hasilnya menunjukkan bahwa teknik meminjam lebih banyak digunakan oleh penerjemah dalam menerjemahkan novel The Wonderful Wizard of OZ adalah jenis pure borrowing. Sementara, naturalized borrowing tidak ditemukan di dalamnya.

Kata Kunci: Analisis, Teknik Borrowing, Penerjemahan

This study is a kind of library research, it aims to find out the of borrowing technique which is used by a translator in translating Frank Baum's novel entitled "The Wonderful Wizard of Oz". It was translated by Dewanti in 2018. The borrowing techniques analyzed in this study were pure borrowing and naturalized borrowing. The data are taken by read repeatedly and made a list of the borrowing words are found, and then explained them cited the sentences both novels. The result shows, the borrowing technigue is more used by the translator in translating the a novel "The Wonderful Wizard of OZ" is pure borrowing. While, the naturalized borrowing is not found in it.

Keywords: Analysis, Borrowing Technique, Translation

Hasil survei Badan Pusat Statistik (BPS) tahun 2012 menunjukkan bahwa 91,58 \% penduduk di atas 10 tahun lebih suka melihat televisi (Kompas, 2016). Penduduk yang suka membaca, baik buku, surat kabar, maupun majalah hanya 17,58\%. Hal ini mengisyaratkan bahwa penduduk Indonesia masih rendah dalam minat baca. Padahal seperti telah diketahui bersama, membaca merupakan jendela dunia. Berbagai informasi dapat diperoleh melalui membaca. Temuan BPS ternyata sejalan dengan hasil kajian Perpustakaan Nasional yang dilakukan tahun 2015. Perpustakaan Nasional melakukan kajian di 12 provinsi dan 28 
kabupaten atau kota di seluruh wilayah Indonesia. Kajian Perpustakaan Nasional menyimpulkan bahwa masyarakat memiliki minat baca dengan kategori rendah, yakni 25,1. Jumlah ini tentu saja sangat memprihatinkan (Kompas, 2016).

Penerjemahan adalah komunikasi makna teks bahasa sumber melalui teks bahasa target yang setara. Bahasa Inggris memiliki perbedaan terminologis (tidak semua bahasa melakukannya) antara penerjemahan (teks tertulis) dan penafsiran (komunikasi lisan atau bahasa isyarat antara pengguna bahasa yang berbeda); dalam perbedaan ini, penerjemahan dapat dimulai hanya setelah kemunculan tulisan di dalam komunitas bahasa.

Seorang penerjemah selalu mengambil risiko memasukkan kata-kata, tata bahasa, atau sintaksis bahasa sumber secara tidak sengaja ke dalam terjemahan bahasa target. Di sisi lain, sikap semacam itu kadang-kadang mengimpor bahasa sumber dan kata pinjaman yang bermanfaat yang memperkaya bahasa target. Para penerjemah, termasuk penerjemah awal teks-teks suci, telah membantu membentuk bahasa yang digunakan kedalam bahasa yang telah diterjemahkan (wikipedia).

Vinay dan Darbelnet dalam Venuti (2008: 84) membagi proses penerjemahan menjadi dua istilah, yaitu terjemahan langsung dan terjemahan oblique (miring). Ada tujuh teknik yang digunakan dalam penerjemahan. Teknik tersebut antara lain teknik terjemahan langsung, terdiri borrowing, calque, dan terjemahan literal. Sedangkan teknik terjemahan oblique (miring) meliputi transposisi, modulasi, kesetaraan, dan adaptasi.

Dalam penelitian ini, peneliti hanya berfokus pada teknik penerjemahan borrowing. Penerjemahan borrowing berarti kata yang diambil langsung dari bahasa lain. Ini digunakan untuk membuat efek gaya. Menurut Molina dan Albir yang dikutip dalam Srikandi (2010: 4), teknik borrowing dibagi dalam dua jenis yaitu pure borrowing (pinjaman murni) dan naturalized borrowing (pinjaman naturalisasi).

Naturalized borrowing dalam penerjemahan dibuat agar sesuai dengan aturan ejaan dalam Bahasa Penerima (BP). Pengalihan kata February dalam bahasa Inggris (Lawrence, 1960: 44), itu setara dengan kata Februari dalam Bahasa Indonesia (Achyar, 2008: 146). Dalam menulis artikel ini, buku teks atau novel dipilih sebagai sumber data. Itu adalah salah satu karya sastra. Penerjemah harus tahu cara agar pembaca tertarik. Oleh karena itu, teknik penerjemahan borrowing diperlukan untuk menjadi metode penerjemahan untuk mengatasi hal tersebut. Itulah alasan mengapa topik penelitian ini adalah Analisis Teknik Borrowing dalam Penerjemahan Novel The Wonderful Wizard of OZ kedalam bahasa Indonesia. Kata borrowing mengacu pada teknik penerjemahan. Penulis novel ini adalah L. Frank Baum. Itu dicetak dan dijilid di Indonesia oleh Percetakan Gramedia, Jakarta. Penerjemah novel ini adalah Prima Sari Woro Dewanti. Semua hak cipta dilindungi oleh PT. Gramedia, Jakrta. Dalam penerjemahan The Wonderful Wizard of $O Z$ ke dalam bahasa Indonesia, peneliti menemukan banyak 
teknik borrowing. Alasan lainnya adalah karena isi novelnya sangat menarik, luar biasa menyentuh hati kita, dan langsung memukau pembaca. Dan juga telah dibuat menjadi film yang sangat menarik. Oleh karena itu, setiap pembaca akan suka jika terjemahannya mudah dimengerti oleh pembaca.

Mengenai teknik borrowing dalam penerjemahan The Wonderful Wizard of OZ ke dalam Bahasa Indonesia, ada beberapa masalah yang perlu dijawab. Permasalahannya adalah (1) jenis teknik borrowing (pinjaman) apa yang digunakan dalam penerjemahan The Wonderful Wizard of $O Z$ ke dalam Bahasa Indonesia dan (2) teknik penerjemahan borrowing (pinjaman) apa yang diterapkan untuk menerjemahkan novel ini.

METODE

\section{PEMBAHASAN}

Penelitian ini adalah jenis penelitian kepustakaan. Hal itu diterapkan untuk mengumpulkan beberapa informasi sebagai data dan teori. Penelitian ini menggunakan pendekatan penelitian kualitatif. Data diambil dari buku teks khususnya novel. Metode kualitatif dilaksanakan dan analisis dijelaskan menggunakan kalimat deskriptif.

Prosedur sistematis dalam melakukan analisis adalah sebagai berikut: (1) membaca novel berulang kali; (2) mengidentifikasi dan mendaftarkan kata atau kalimat yang termasuk dalam pure borrowing dan naturalized borrowing; (3) mengklasifikasikan katakata menjadi pure borrowing dan naturalized borrowing; (4) menganalisis prosedur borrowing; (5) menggambar beberapa kesimpulan berdasarkan hasil analisis.

Analisis ini didasarkan pada beberapa teori oleh beberapa ahli bahasa. Teori prosedur borrowing (peminjaman) oleh Vinay dan Darbelnet dikutip dalam Srikandi (2010: 3).

Paling tidak, analisis pada bagian ini dilakukan berdasarkan pada integrasi standar unsur-unsur kata yang diserap kedalam sistem bahasa Indonesia yang mendukung keberadaan kata borrowing (pinjaman) dalam suatu penerjemahan.

\section{Jenis Borrowing (Pinjaman)}

Sebagaimana dinyatakan dalam konsep, penelitian ini berfokus pada dua jenis: pure borrowing (pinjaman murni) dan naturalized borrowing (pinjaman naturalisasi), yang secara rinci diterapkan ke dalam tiga bagian kata (elemen) borrowing (sebagaimana dianalisis dalam bab ini) ke dalam bahasa Indonesia dari bahasa asing (yang sebagian besar dipinjam atau diserap dari bahasa Inggris), sebagaimana didukung oleh integrasi standar penyerapan elemenkata yang disahkan oleh Pemerintah Indonesia sebagaimana dinyatakan dalam PUEBIYD oleh P3B. 
Penerapan Teknik Borrowing dalam Penerjemahan dari Novel The Wonderful Wizard of $O Z$ kedalam Bahasa Indonesia

Untuk penjelasan lebih lanjut, analisis di bawah ini didasarkan pada data yang terkait dengan empat klasifikasi prosedur borrowing yang diterapkan dalam penerjemahan The Wonderful Wizard of $O Z$ ke dalam Bahasa Indonesia.

\section{Pure Borrowing (Peminjaman Murni)}

Tabel di bawah ini menunjukkan teknik pure borrowing (Peminjaman Murni) yang ditemukan dalam data.

Tabel 1. Teknik Pure Borrowing

\begin{tabular}{|c|l|l|}
\hline No. & Bahasa Sumber (BS) & \multicolumn{1}{|c|}{ Bahasa Target (BT) } \\
\hline 1 & Gingham & Gingham \\
\hline 2 & Sunbonnet & Sunbonnet \\
\hline 3 & Poppy & Poppy \\
\hline 4 & Apron & Apron \\
\hline 5 & Winkie & Winkie \\
\hline 6 & Ep-pe, pep-pe, kak-ke! & Ep-pe, pep-pe, kak-ke! \\
\hline 7 & Hil-lo, hal-lo, hel-lo! & Hil-lo, hal-lo, hel-lo! \\
\hline 8 & Ziz-zy, zuz-zy, zik! & Ziz-zy, zuz-zy, zik! \\
\hline 9 & Ventriloquist & Ventriloquist \\
\hline 10 & Balloonist & Balloonist \\
\hline
\end{tabular}

Jumlah dari pure borrowing (peminjaman murni) terdiri dari 7 kata dan 3 kalimat.

\section{Analisis:}

Dalam hal ini, kata-kata pure borrowing (murni dipinjam) dari kata aslinya BS ke BT. Ini disebut metode terjemahan langsung, yang tampaknya tidak dapat diterjemahkan ke dalam BT. Namun, konsep selalu tersedia di BT juga. Ketika ada konsep yang tidak diketahui, tetapi telah diketahui oleh pembaca BT dan telah dimungkinkan dapat diterima dalam penerjemahan berdasarkan pada budaya BT. Seperti yang dapat kita lihat dari contoh: gingham, sunbonnet, poppy, apron, winkie, ventriloquist, dan balloonist. (Seluruh contoh ini telah dianalisis secara kolektif).

(1) Teks BS:

It was gingham with checks of white and bleu; and although the blue was somewhat faded with many washings, it was still a pretty frock. (p. 21-22)

Teks BT :

Gaun itu terbuat dari kain gingham, dengan motif kotak-kotak kecil berwarna biru putih: walaupun warna birunya sedikit pudar karena sering dicuci, gaun itu tetap cantik. (p. 21) 
Kata BS gingham berarti adalah kain tenunan polos seimbang menengah-berat yang terbuat dari kapas dicelup atau benang katun-campuran (https://en.wikipedia.org/ diakses 01/15/2019 6: 42 AM) harus diterjemahkan ke dalam kain genggang dalam teks BT yang tampaknya memiliki konsep serupa dalam Bahasa Indonesia (https://kbbi.web.id/ diakses 01/15/2019 6:50 AM). Dalam hal ini, sebagai kata borrowing (pinjaman), penerjemah menggunakan kata khusus gingham tanpa sistem penyesuaian ejaan dan bunyi. Penerjemahan ini diterima dalam BT karena penerjemah menerjemahkan kata gingham menjadi kain gingham. kata gingham itu sendiri tidak umum saat ini dalam budaya BT, namun telah dikenal di BT sebagai kain genggang. Jadi, penerjemahannya perlu diubah menjadi kain genggang.

(2) Teks BS :

The girl washed herself carefully, dressed herself in the clean gingham, and tied her pink sunbonnet on her head. (p. 22)

Teks BT:

Si gadis kecil membasuh tubuhnya baik-baik, mengenakan gaunnya, lalu mengikat sunbonnet merah muda miliknya di kepala. (p. 21)

Kata sunbonnet in the teks BS artinya nama untuk berbagai jenis penutup kepala untuk laki-laki dan perempuan - lebih sering perempuan — dari abad pertengahan hingga saat ini (https://en.wikipedia.org/ diakses 01/15/2019 07: 18 AM). Dalam KBBI kata bonet berarti; (1) kopiah atau topi kecil terbuat dari kain halus dan tanpa pinggiran; (2) Kat tutup kepala bersudut tiga atau empat yang dipakai rohaniwan Katolik (untuk pastor berwarna hitam, untuk uskup berwarna ungu, untuk kardinal berwarna merah, dan untuk paus berwarna putih) (https://kbbi.web.id/ accessed 01/15/2019 07 : 25 AM). Untuk memperjelas arti kata sunbonnet, penerjemah harus menggunakan teknik naturalized borrowing (peminjaman naturalisasi) dalam menerjemahkannya dengan menghilangkan satu huruf ' $n$ ' menjadi 'bonet'. Dan akan lebih jelas jika penerjemah menerjemahkan kata 'sunbonnet' menjadi 'topi bonet'.

(3) Teks BS :

The deadly poppy field. (p. 60)

Teks BT :

Padang bunga poppy yang mematikan. (p.73)

Kata poppy dalam teks BS berarti tanaman berbunga di subfamili Papaveroideae dari keluarga Papaveraceae (https://en.wikipedia.org/ diakses 01/15/2019 11: 36 AM). 
Tidak ada kata yang setara dalam KBBI untuk menggantikan kata poppy, tetapi dalam membuat makna kata poppy lebih jelas, penerjemah menerjemahkan kata poppy dalam BT menjadi frasa 'bunga poppy'. Ini menunjukkan bahwa poppy adalah sejenis bunga, masih setara dengan BS seperti yang dinyatakan dalam Wikipedia di atas.

(4) Teks BS :

Indeed, the Tin Woodman began to cry, but fortunately remembered that hemight rust, and so dried his tears on Dorothy's apron. (p.62)

Teks BT :

Tentu saja Manusia Kaleng mulai menangis, tetapi untungnya teringat kalau dia bisa berkarat, sehingga dia mengeringkan air matanya dengan apron yang Dorothy pakai. (p.75)

Kata apron dalam teks BS berarti pakaian yang dikenakan di atas pakaian lain dan terutama menutupi bagian depan tubuh (https://en.wikipedia.org/ diakses 01/15/2019 11: 50 AM). Sementara, di KBBI kata apron berarti tempat parkir pesawat udara (https://kbbi.web.id/ diakses 01/15/2019 07: 52 AM). Dalam hal ini, penerjemah membuat kesalahan dengan menerjemahkan kata apron dari BS menjadi kata yang sama 'apron' ke dalam BT. Jadi, dalam menyelesaikan masalah terjemahan ini, penerjemah harus menerjemahkan kata 'apron' dari BS ke dalam frasa 'kain apron' dalam BT. Ini bertujuan untuk membedakan kata 'apron' sebagai jenis pakaian atau kain dengan 'apron' sebagai tempat parkir pesawat.

(5) Teks BS :

"There is only one thing we can do," returned the Lion, "and that is to go to the land of the Winkies, seek out the Winked Witch, and destroy her." (p. 97)

Teks BT :

"Hanya ada satu hal yang dapat kita perbuat," sahut Singa, "yaitu pergi ke negeri para Winkie, mencari si Penyihir Jahat, dan memusnahkannya." (p. 122-123)

Kata Winkies di Wikipedia memiliki beberapa makna, penulis hanya memilih dua makna. (1) Winkie berarti tempat dalam novel Wizard of $\mathrm{Oz}$ karya L. Frank Baum dan orangorang yang menghuninya; (2) nama panggilan dari pendukung klub sepakbola Winchester College (https://kbbi.web.id/ diakses 01/15/2019 12: 22 PM). Tidak ada kata yang setara di KBBI untuk menggantikan kata Winkies. Jadi, menerjemahkan kata 'Winkies' dari BS menjadi frase 'para Winkie' di BT dapat diterima. 
(6) Teks BS:

Then she stood upon her left foot and said slowly : "Ep-pe, pep-pe, kak-ke!". (p. 105)

Teks BT :

Lalu dia berdiri di atas kaki kiri dan berkata lambat-lambat : “Ep-pe, pep-pe, kak-ke!" (p. 134)

Kalimat "Ep-pe, pep-pe, kak-ke!" tidak ditemukan di BS dan BS. Untuk membuat pemahaman yang lebih jelas pada penutur BT, penerjemah harus menerjemahkan kalimat "Then she stood upon her left foot and said slowly : "Ep-pe, pep-pe, kak-ke!" menjadi "Lalu dia berdiri di atas kaki kiri dan mengucapkan mantranya dengan lamban : "Ep-pe, pep-pe, kak-ke!".

(7) Teks BS :

Next she stood upon her right foot and said : "Hil-lo, hal-lo, hel-lo!". (p. 105)

Teks BT :

Selanjutnya dia berdiri di atas kaki kanan dan berkata "Hil-lo, hal-lo, hel-lo!" (p. 134)

Kalimat "Hil-lo, hal-lo, hel-lo!" Tidak ditemukan di BS dan BT. Untuk membuat pemahaman yang lebih jelas pada penutur BT, penerjemah harus menerjemahkan kalimat "Next she stood upon her right foot and said : "Hil-lo, hal-lo, hello!" menjadi "Selanjutnya dia berdiri di atas kaki kanan dan mengucapkan mantra "Hil-lo, hal-lo, hel-lo!".

(8) Teks BS :

After this she stood upon both feet and cried in a loud voice : “Ziz-zy, zuz-zy, zik!'”. (p. 105)

Teks BT :

Setelah itu dia berdiri di atas kedua kaki dan berteriak lantang : “Ziz-zy, zuz-zy, zik!'” (p. 134)

Kalimat "Ziz-zy, zuz-zy, zik!" Tidak ditemukan baik pada BS maupun pada BT. Untuk membuat pemahaman yang lebih jelas kepada para pembicara BT, penerjemah harus menerjemahkan kalimat-kalimatnya "After this she stood upon both feet and cried in a loud voice : “Ziz-zy, zuz-zy, zik!'”. (p. 105) menjadi "Setelah itu dia berdiri di atas kedua kaki dan mengucapkan mantranya dengan berteriak lantang : "Ziz-zy, zuz-zy, zik!'”.

(9) Teks BS :

"Oh, I am a ventriloquist," said the little man. (P.134) 
Teks BT :

"Oh, aku seorang ventriloquist," kata si pria kecil. (p. 173)

Kata ventriloquist BS berarti orang yang menyediakan hiburan dengan menggunakan ventriloquism untuk melakukan percakapan yang tampak jelas dengan boneka yang dimanipulasi tangan (https://www.merriamweslter.com/dictionary/ diakses 01/15/2019 4: 12 PM) . Tidak ada kata yang setara dalam BT untuk menggantikan kata 'ventriloquist'. Jadi, teknik yang digunakan oleh penerjemah untuk meminjam kata ventriloquist dari BS ke BT, seorang ventriloquist diterima. Kata seorang akan membuat makna ventriloquist dipahami oleh penutur BT.

(10) Teks BS :

"After a time," continued Oz, "I tired of that, and became a balloonist." (p. 135)

Teks BT :

"Setelah beberap lama," lanjut Oz, "aku merasa bosan dengan itu, lalu aku menjadi balloonist." (p. 175)

Kata balloonist dalam BS berarti seseorang yang mengoperasikan atau mengendarai balon (https://www.merriam-weslter.com/dictionary/ diakses 01/15/2019 4: 22 PM). Tidak ada kata yang setara dalam BT untuk menggantikan kata 'balloonist'. Teknik yang digunakan oleh penerjemah untuk meminjam kata balloonist dari BS ke BT bersifat ambigu. Jadi, penerjemah harus menerjemahkannya dalam BT sebagai 'manusia balloonist ' atau dengan menerjemahkannya menjadi 'manusia balon' tanpa menggunakan teknik pinjaman.

\section{Naturalized Borrowing (Pinjaman Naturalisasi)}

Based on analysis result, the writer did not find any borrowing technique that used by the translator in translating the novel "The Wonderful Wizard of $\boldsymbol{O Z}$ " into Indonesian. So, this section can not be explained by using the data analysis detaily.

Berdasarkan hasil analisis, penulis tidak menemukan teknik naturalized borrowing (pinjaman natulisasi) yang digunakan oleh penerjemah dalam menerjemahkan novel "The Wonderful Wizard of $\boldsymbol{O Z}^{\prime \prime}$ ke dalam Bahasa Indonesia. Jadi, bagian ini tidak bisa dijelaskan dengan menggunakan analisis data secara rinci.

Berdasarkan temuan dalam analisis di atas, beberapa kesimpulan dapat ditarik seperti di bawah ini. Istilah leksikal yang digunakan dalam BT terdiri dari kata-kata pinjaman (borrowing) yang umumnya diasimilasi dengan BT, dan sebagiannya menjadi kata baru bagi penutur BT. Terutama, ada modifikasi yang 
disengaja dan tidak disengaja dalam proses penerjemahan. Berdasarkan analisis hasil penelitian ini, dapat dikatakan bahwa jenis pinjaman (borrowing) lebih banyak digunakan oleh penerjemah dalam menerjemahkan novel The Wonderful Wizard of $O Z$ adalah jenis pure borrowing (pinjaman murni). Sementara, pinjaman yang dinaturalisasi tidak ditemukan di dalamnya.

Ada beberapa masalah konsistensi dalam meminjam istilah ke dalam bahasa Indonesia tanpa merujuk budaya BT, bahkan tanpa merujuk ke EYD. Akibatnya, lebih baik bagi penerjemah untuk menggunakan Kaidah Bahasa Indonesia (aturan EYD) sebagai referensi untuk mengadopsi teknik borrowing (pinjaman). Selain itu, fakta menunjukkan bahwa tidak semua kata-kata baru itu dapat dengan benar-benar diterjemahkan dengan jelas ke dalam BS. Selanjutnya, lebih baik bagi penerjemah untuk mencoba terlebih dahulu dengan menemukan padanan kata dalam BT sebelum memutuskan untuk mengadopsi strategi peminjaman (borrowing) atau penyerapan.

\section{DAFTAR PUSTAKA}

Achyar, Arfan. 2008. Lady Chatterley's Lover. Jakarta : Alvabet.

Baum, L. Frank \& Dewanti. 2018. The Wonderful Wizard of Oz. PT : Translated into Indonesian by Dewanti . Jakarta: Elex Media Komputindo

(Kompas Gramedia).

Baum, L. Frank. 2017. The Wonderful Wizard of Oz: English Classics . Jakarta: Gramedia Pustaka Utama (Kompas Gramedia).

Srikandi, Cut N. 2010. Borrowing in the Translation of D. H. Lawrence's Lady Chatterley's Lover into Indonesian: A Thesis. Sumatra Utara: University of Nort Sumatra.
Baker, Mona. 1992. In Other Words: A Coursebook on Translation.New York: Routledge.

https://en.wikipedia.org/wiki/Translation acessed 08/01/19 9:58AM

https://en.wikipedia.org/ accessed 01/15/2019 6: 42 AM

https://kbbi.web.id/ accessed 01/15/2019 6:50 AM

https://www.merriamweslter.com/dictionary/ accessed 01/15/2019 4: 12 PM 